\title{
Expression dynamics of caveolin-1 in fibroblasts of new- born rats with chronic lung disease and its impact on lung fibroblast proliferation ${ }^{1}$
}

\author{
Xin Wang', Jian-Hua Fu", Xin-Dong Xue ${ }^{\prime \prime \prime}$
}

\begin{abstract}
'MD, Department of Pediatrics, Shengjing Hospital, China Medical University, Shenyang, China. Conception and design of the study, technical procedures, acquisition and analysis of data, manuscript writing.

"MD, Department of Pediatrics, Shengjing Hospital, China Medical University, Shenyang, China. Analysis and interpretation of data, manuscript writing.

I'Professor, Department of Pediatrics, Shengjing Hospital, China Medical University, Shenyang, China. Conception, design, intellectual and scientific content of the study; critical revision; final approval the manuscript.
\end{abstract}

\begin{abstract}
Purpose: To evaluate the changes of caveolin-1 in lung fibroblasts in newborn Wistar rats when exposed to hyperoxic conditions, as well as lung fibroblasts cell cycle.

Methods: One hundred newborn Wistar rats were randomly divided (50 rats/group) into experimental and control groups, exposed to hyperoxic conditions or normal air, respectively. The fraction of inspired oxygen $\left(\mathrm{FiO}_{2}\right)$ in the experimental group was $90 \%$, whereas this value was $21 \%$ in the control group. Lung fibroblasts were collected on days 3, 7, and 14 of the experiment. Caveolin-1 expression dynamics in lung fibroblasts was assayed in each group by immunofluorescence and Western blot analyses. Flow cytometry (FCM) was used to assess the proportions of lung fibroblasts at different stages of the cell cycle.

Results: On day 3, no significant difference in caveolin-1 expression was observed between the hyperoxic and control groups; however, on days 7 and 14, caveolin-1 expression was significantly lower in the hyperoxic group than in the control $(P<0.05)$. No apparent differences were observed in caveolin-1 expression in the control group at the different time points. Using FCM analysis, we showed that the proportion of lung fibroblasts in G0/G1 phase in the hyperoxic group decreased compared to that of the control group on day 7 , while the proportion of $S$-phase cells increased $(P<0.05)$. These differences were more significant when the groups were compared on day $14(\mathrm{P}<0.01)$.
\end{abstract}

Conclusion: After seven days the exposure to hyperoxic conditions, lung fibroblasts proliferated and caveolin-1 expression decreased.

Key words: Lung. Fibroblasts. Pulmonary Fibrosis. Caveolin 1. Cell Cycle. Rats. 


\section{Introduction}

Although the pathogenesis of chronic lung disease (CLD) in preterm children is not well understood, its delayed pathological outcome, pulmonary fibrosis, is unquestionable ${ }^{1}$. If we find what is the main cause of the pulmonary fibrosis, the treatment would be more effect and lead to better prognosis.

The prevention and treatment of pulmonary fibrosis has posed a significant challenge in the treatment of CLD with noninterruption study ${ }^{2}$. Lung fibroblasts (LFs) are recognized as effector cells of pulmonary fibrosis ${ }^{3}$. Pulmonary fibrosis is associated with excessively proliferating LFs that deposit in the interstitial lung or replace the normal lung epithelium ${ }^{4}$. Directly culturing LFs in vitro at high concentrations of oxygen can inhibit cell proliferation ${ }^{5}$, while the growth of LFs in human or animal lung tissues that have inhaled high concentrations of oxygen show the opposite effect. The primary culture of LFs from CLD newborn rats is the only feasible method to study the mechanism controlling this excessive proliferation at the cellular level. In the present study, we established a reliable primary cell culture method for LFs derived from CLD newborn rats to create a platform to study the mechanism of CLD stromal cell fibrosis in vitro.

Caveolin-1, which is highly expressed in type I alveolar epithelial cells, endothelial cells, and fibroblasts, is associated with cell proliferation ${ }^{6}$. Thus, we questioned whether abnormal expression levels of caveolin-1 correlated with the pulmonary LF hyperproliferative process that occurs during CLD stromal cell fibrosis ${ }^{7}$. In this study, the expression levels of caveolin-1 in LFs at different stages of hyperoxia-induced CLD development in rats were examined to investigate its role in lung fibroblast proliferation and in the incidence and development of pulmonary fibrosis. This study was to find the changes of caveolin-1 in lung fibroblasts in newborn Wistar rats when exposed to hyperoxic conditions, as well as lung fibroblasts cell cycle to find if more fibroblasts conversed into myofibroblasts.

\section{- Methods}

The animal use protocol has been reviewed and approved by the Institutional Animal Care and Use Committee (IACUC) of China Medical University (Permit Number: 20060828001). This study was carried out in strict accordance with the recommendations in the Guide for the Care and Use of Laboratory Animals of the National Institutes of Health.

One hundred newborn Wistar rats were provided by the Department of Animal Laboratory. All surgery on rats was performed under pentobarbital sodium (3\% pentobarbital sodium $1 \mathrm{ml} / 100 \mathrm{~g}$ mouse, intraperitoneal injection) anesthesia, and all efforts were made to minimize suffering.

Healthy neonatal Wistar rats were randomly divided into two groups (50 rats/ group), the experimental and control groups that were exposed to hyperoxic condition and normal air, respectively. The newborn Wistar rats in the experimental group, together with female rats, were placed in an oxygen tank after birth. The tank had a continuous input of oxygen and the fraction of inspired oxygen $\left(\mathrm{FiO}_{2}\right)$ was maintained at $90 \%$ (U.S. OM-25ME-type oxygen analyzer, Maxtec, Salt Lake City, Utah, United States of America). $\mathrm{CO}_{2}$ was absorbed using soda lime to maintain the concentration below $0.5 \%$ (Dapex gas analyzer). The temperature was maintained between 22 and $25^{\circ} \mathrm{C}$ and humidity was maintained at $50-70 \%$. The tank was opened for $0.5 \mathrm{~h} / \mathrm{d}$ to provide water and food and to change the padding. The female rats were interchanged with those of the control group every day to avoid oxygen toxicity. The control group was exposed to air ( $\mathrm{FiO}_{2}$ of $\left.21 \%\right)$, but the 
other methods and conditions were the same as those of the experimental group.

The pulmonary fibrosis scoring system was taken into concern to determine the chronic lung disease, which was implemented by optical microscope $(100 x)$ and the results ranged from 0 point to 8 points. Grading criteria: 0 were normal lung tissue; 1 were fibrosis of alveolar and terminal bronchiole, 2-3 was moderate fibrosis without any change of alveolar structure; 4-5 was moderate fibrosis with alveolar structure change, also with fiber bundle or fibrous nodule formation; 6-7 was severe fibrosis with severe alveolar structural changes; 8 was diffuse fibrosis,

Isolation, culture, and identification of LFs in vitro

We followed the method reported by Kelleher et al. ${ }^{8}$ but with the following modifications. Wistar rats $^{2,3}$ were selected at random on days 3,7 and 14 after the experiment had commenced. pentobarbital sodium (3\%) was injected intraperitoneally (1 $\mathrm{mL} / 100 \mathrm{~g}$ body weight) to sacrifice the rats. The lungs were immediately removed under aseptic conditions, placed in pre-cooled sterile petri dishes containing D-Hank's solution, and washed repeatedly to remove residual blood. Non-lung stromal tissues were isolated simultaneously. The washed lung tissues were transferred to sterile beakers, each specimen was cut to a size of $1 \mathrm{~mm}^{3}$, and was gently suspended in D-Hank's solution. The supernatant was aspirated until the tissues were naturally pelleted. This was repeated 2-3 times, before $0.25 \%$ trypsin was added. Tissues were digested for $30 \mathrm{~min}$ in a $37^{\circ} \mathrm{C}$ oscillating water bath and digestions were terminated by adding an equal volume of Dulbecco's modified Eagle medium (DMEM) containing $10 \%$ fetal calf serum. Digests were passed through a 200-mesh filter, transferred to a tube for centrifugation $\left(4^{\circ} \mathrm{C}, 80 \mathrm{xg}, 5 \mathrm{~min}\right)$, and the supernatant was discarded. The pellets were resuspended in DMEM containing 10\% FBS, the cell concentrations were adjusted as $2 \times 10^{5}$ cells $/ \mathrm{ml}$, and then cells were inoculated into $5 \mathrm{~mL}$ cell culture flasks. Flasks were placed in an incubator with $5 \% \mathrm{CO}_{2}$ at $37^{\circ} \mathrm{C}$ for 12 h. Approximately $80 \%$ of the adherent cells changed into LFs. The culture medium was changed daily. The cell morphology and the basic growth conditions were observed using an inverted microscope (Olympus, Tokyo, Japan).

Cell growth was monitored using microscopy. The culture medium was discarded when the cells were close to fusion (80\%). D-Hank's solution was used to wash the cells and $1 \mathrm{~mL} 0.25 \%$ trypsin was added. Cells were exposed to trypsin for 2-5 $\mathrm{min}$ at room temperature until the cytoplasm retracted, cell bodies rounded, and cell gaps enlarged. The trypsin was then aspirated, and $10 \mathrm{~mL}$ of DMEM containing $10 \%$ fetal bovine serum was added to terminate the digestion. Cells were gently pipetted against the wall of the tube. After the cells were dissociated, the suspension was aliquoted into the flasks and the suspension was diluted 1:2 or 1:3 in culture medium. Flasks were placed into a $\mathrm{CO}_{2}$ incubator, and the medium was changed after $2 \mathrm{~h}$ to remove non-adherent cells. The third-generation cells at a purity of more than $95 \%$ were used in the experiment.

The second-generation LFs close to fusion were digested using trypsin, and the cell concentration was adjusted to $1 \times 10^{5} / \mathrm{mL}$. One milliliter of the cell suspension was added to sixwell plates containing sterile coverslips. Plates were placed in $5 \% \mathrm{CO}_{2}$ in a $37^{\circ} \mathrm{C}$ incubator, and the coverslips coated in cells were collected the following morning. Cells were washed in phosphate-buffered saline (PBS) three times and were fixed in $4 \%$ paraformaldehyde for $30 \mathrm{~min}$. Vimentin expression was detected by immunohistochemistry, using the 
streptavidin-peroxidase method (Beijing Zhongshan Golden Bridge Biotechnology Co., Ltd.). After incubation for 10 minutes at room temperature with goat serum, the primary antibody of CAV-1 (1:160) was added with tissue for the whole night, then the secondary fluorescent antibody was added in darkroom, which was incubated for 90 minutes, before taken the picture, DAPI was added and incubated for 10 minutes at $37^{\circ} \mathrm{C}$.

\section{Caveolin-1 immunofluorescence staining}

Cell-coated coverslips were washed in distilled water three times (5 min/wash). 5\% normal goat serum was incubated with the coverslips at room temperature for $10 \mathrm{~min}$. Vimentin was the antibody to test the caveolin-1 expression. Vimentin (1:100, Beijing Zhong Shan -Golden Bridge Biological Technology CO., LTD) and caveolin-1 antibodies (1:160, Santa Cruz Biotechnology, Santa Cruz, CA, USA) were applied and coverslips were placed at $4^{\circ} \mathrm{C}$ overnight. Coverslips were washed in PBS 3 times (5 min/wash). Fluorescent secondary antibodies (1:50) were added in a darkroom and were incubated with the coverslip for 90 min in a $37^{\circ} \mathrm{C}$ humidified chamber. Coverslips were washed in PBS 3 times (5 min/wash). Excess liquid was removed, and $50 \mu \mathrm{L} 4^{\prime}$, 6-diamidino-2-phenylindole (DAPI) was added to each coverslip. Coverslips were incubated in DAPI for $10 \mathrm{~min}$ in a $37^{\circ} \mathrm{C}$ humidified chamber and were then washed in PBS 3 times (5 min/ wash). Cells were examined and photographed using a fluorescence microscope (Olympus Corporation, Tokyo, Japan).

Western blot analysis of caveolin-1 levels in LFs

Proteins were extracted from the cells according to the protocol provided by the KGI whole protein extraction kit (Nanjing KGI Biotechnology Development Co., Ltd.). The
BCA method was used to measure the protein concentration in the samples (Haibi Skylight Biotechnology Co., Ltd.). A $15 \%$ separating gel $(20 \mathrm{~mL})$ and $5 \%$ stacking gel $(10 \mathrm{~mL})$ were prepared, and $20 \mu \mathrm{L}$ of protein sample was loaded into each well. Electrophoresis was performed (Bio-Rad-PAC300; Bio-Rad, Hercules, CA, USA) and proteins were then transferred to a nitrocellulose membrane. The membrane was washed once and then blocked using (Tris-buffered saline containing $0.1 \%$ Triton Tween 20) containing 5\% nonfat milk for $1 \mathrm{~h}$ at room temperature. The membrane was washed in TBST 3 times (15 min/wash) and then incubated with caveolin-1 antibodies (1:200; Santa Cruz Biotechnology, Santa Cruz, CA, USA), at $4^{\circ} \mathrm{C}$ overnight.

Horseradish peroxidase-conjugated secondary antibodies were added (1:2000; BeijingZhongshan Golden Bridge Biotechnology Co., Ltd.) for $2 \mathrm{~h}$ at room temperature. Membranes were then washed 3 times in TBST (15 min/wash), and proteins were detected using enhanced chemiluminescence reagent.

Images were obtained using the MFChemiBIS 3.2 electrophoresis gel image analysis system (DNR Bio-Imaging Systems, Mahale HaHamisha, Israel). An imaging data analysis system (Universal Imaging Proportion, Molecular Devices, Sunnyvale, CA, USA) was used to record the gray value of each protein band and quantitative analysis was then performed. Protein content $=$ gray value of sample protein/gray value of $\beta$-actin in the same sample.

\section{Flow cytometric analysis of cell cycle}

Cells belonging to each group were collected in the logarithmic growth phase and digested in $0.25 \%$ trypsin (Santa Cruz). Prepared cell suspensions were adjusted to $1 \times 10^{6}$ cells $/ \mathrm{mL}$ and then centrifuged for 5 $\min$ at $1000 \mathrm{rpm}$ at $4^{\circ} \mathrm{C}$. Cells were washed twice in PBS and fixed in $5 \mathrm{~mL}$ of $70 \%$ ethanol 
overnight at $4^{\circ} \mathrm{C}$. Subsequently, the cells were centrifuged the following day and resuspended in PBS. RNase (Sigma, St. Louis, MO, USA) was added to a final concentration of $50 \mu \mathrm{g} / \mathrm{mL}$, and cells were placed in a $37^{\circ} \mathrm{C}$ water bath to allow the digest to proceed for $30 \mathrm{~min}$. Propidium iodide (Sigma) was added to the cells at a final concentration of $100 \mu \mathrm{g} / \mathrm{mL}$. Cells were stained in an ice bath in the dark for $30 \mathrm{~min}$. Cells were then analyzed using a flow cytometer (BD, Franklin Lakes, USA) to detect changes in the cell cycle (BD CellQuest software).

\section{Statistical analysis}

SPSS13.0 software was used to perform statistical analyses. Data are presented as the mean \pm standard deviation. The two samples were compared using $t$-tests. Single factor analysis of variance was used to compare samples. $\mathrm{P}<0.05$ was considered statistically significant.

\section{- Results}

Evaluation of the chronic lung disease in rats model

According to the score system, the results of the control group and hyperoxic group showed that on day 14 , there was a significant difference between 2 groups, and the score was higher in hyperoxic group (Table 1).

Table 1 - The score of lung fibrosis $(\bar{X} \pm S)$.

\begin{tabular}{llll}
\hline Groups & Day 3 & Day 7 & Day 14 \\
\hline $\begin{array}{l}\text { Air group } \\
\text { ( } n=10)\end{array}$ & $0.42 \pm 0.02$ & $0.53 \pm 0.15$ & $0.52 \pm 0.21$ \\
$\begin{array}{l}\text { Hyperoxic } \\
\text { group }(n=10)\end{array}$ & $0.46 \pm 0.13$ & $0.68 \pm 0.22$ & $4.21 \pm 0.48^{*}$ \\
\hline
\end{tabular}

Note: Compare with control group, $* P<0.05$.

\section{Morphology and identification of primary cultured rat LFs}

Dynamic LFs were shuttle- or starshaped, but were not stained by trypan blue. The LFs possessed long processes and oval nuclei and showed radial or fence-like arrangement in the center of the culture. No significant changes in cell morphology were observed in the control and hyperoxic groups. Immunohistochemical analysis showed that vimentin was present in cells with brown cytoplasm and silk nets. The purity of cells the third-passage cells were greater than $95 \%$. Up to $95 \%$ of cells were stained using immunofluorescence (Figure 1).

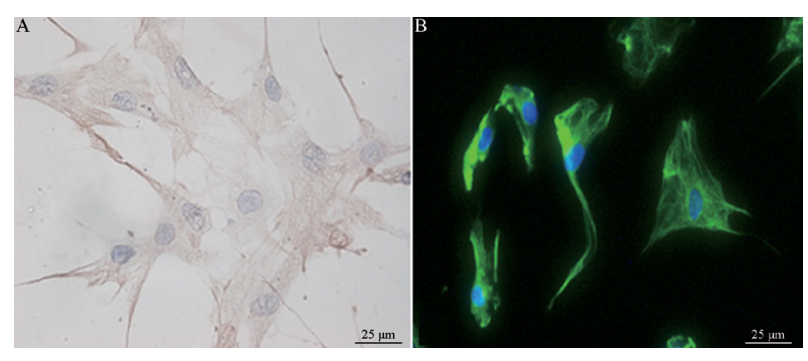

Figure 1 - Vimentin. A. IHC, B. Immunofluorescent staining $x 400$.

\section{Localization of caveolin-1 in hyperoxic LFs}

Caveolin-1 was expressed in both the nuclei and cytoplasm of LFs. On day 3, the hyperoxic group had no significant difference in caveolin-1 level compared to the corresponding control group. Caveolin-1 expression in hyperoxic cells on days 7 and 14, however, was significantly lower than in that the control group $(P<0.05)$. Caveolin-1 expression did not significantly differ in the control group on different days. No significant difference was observed in the hyperoxic group on days 3 and 7; however, caveolin-1 expression in hyperoxic 
cells was significantly lower on day 14 than on days 3 and 7 (Figure 2).

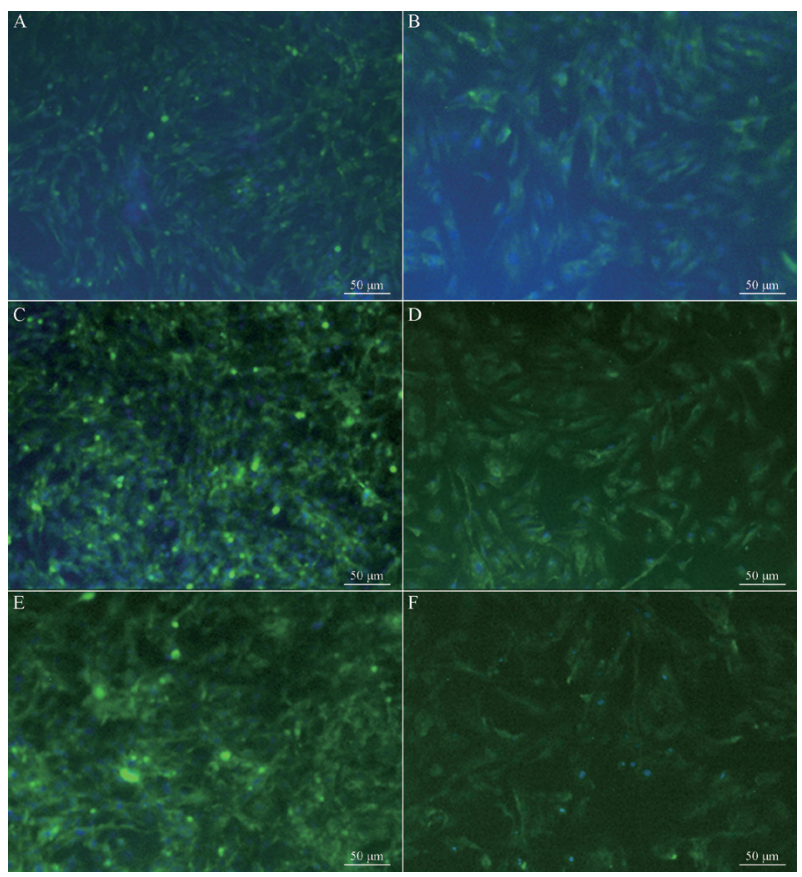

Figure 2 - Caveolin-1 by immunofluorescent staining (A: control $3 \mathrm{~d}$; B: experiment $3 \mathrm{~d}$; C: control $7 \mathrm{~d}$; D: experiment 7 d; E: control 14 d; F: experiment 14 d, $x 200)$.

\section{Western blot}

The hyperoxic group on day 3 showed no significant difference in caveolin-1 level from that of the corresponding control group. However, caveolin-1 expression in the hyperoxic group on days 14 was significantly lower than that of the control group $(P<0.05)$. Caveolin-1 expression was not significantly different in the control group on different days. No significant difference in caveolin-1 level was observed in the hyperoxic group on days 3 and 7, but caveolin-1 expression was significantly lower in the hyperoxic group on day 14 than on days 3 and 7 (Figure 3, Table 2).

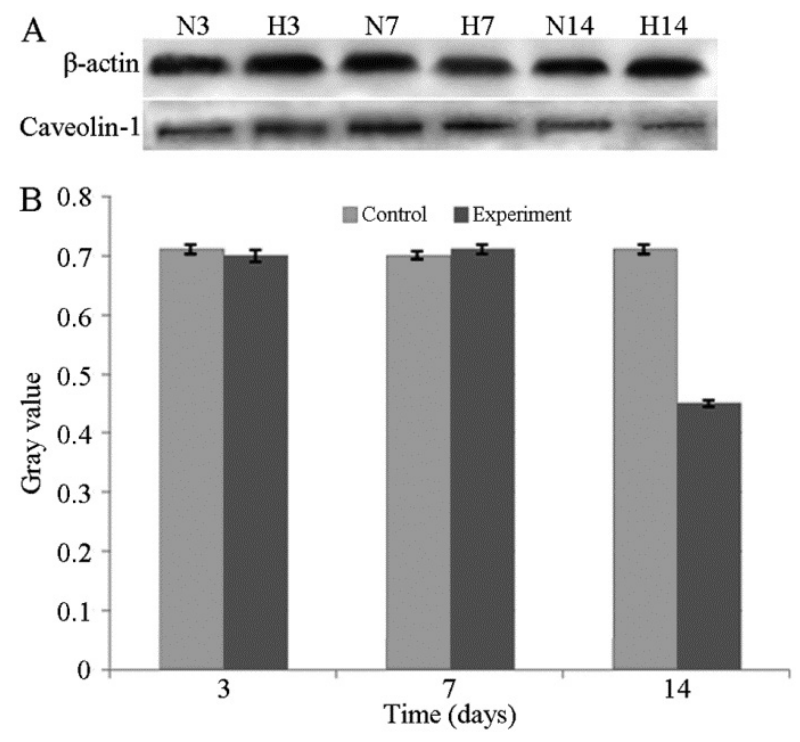

Figure 3 - Gray value of caveolin-1 expression in different groups ( $※$ compare with control, $\mathrm{P}<0.05$ ).

Table 2 - Caveolin-1 dynamic expression of lung fibroblasts detected by western blot ( $\bar{X}$ $\pm s)$.

\begin{tabular}{llll}
\hline Group & $\mathbf{3}$ day & $\mathbf{7}$ day & 14 day \\
\hline $\begin{array}{l}\text { Control } \\
(n=10)\end{array}$ & $0.71 \pm 0.007$ & $0.70 \pm 0.007$ & $0.71 \pm 0.008$ \\
$\begin{array}{l}\text { Hyperoxic } \\
(n=10)\end{array}$ & $0.70 \pm 0.010$ & $0.71 \pm 0.008$ & $0.45 \pm 0.005^{*}$ \\
\hline Note: compare with the control group, ${ }^{*} P<0.05$.
\end{tabular}

Cell cycle changes of $L F$

Flow cytometry (FCM) analysis showed that the percentage of LFs in the G0/G1 phase in the hyperoxic cells on day 7 was lower compared to the control group on day 7 , while the proportion of the $S$ phase cells increased $(P<0.05)$. These changes were more significant $(P<0.01)$ in the hypoxic group on day 14 (Figure 4, Table 3). 

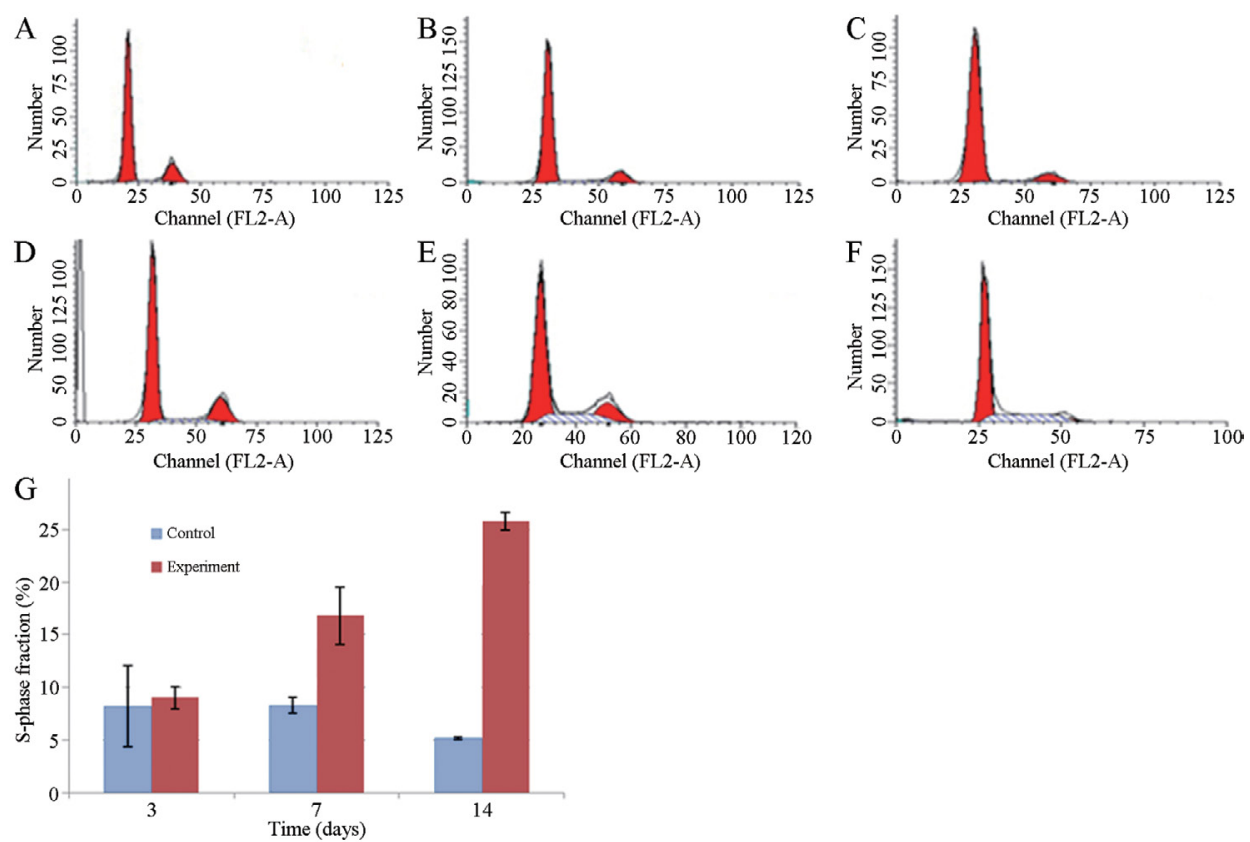

Figure 4 - S-phase fraction (A: control 3 d, B: control 7 d, C: control 14 d, D: experiment 3d; E: experiment 7 d, F: experiment $14 \mathrm{~d})(※ v$ v the control, $\mathrm{P}<0.05)$.

Table 3 - Percentage of LF cell cycle in each group showing by FCM (\%) $(\vec{x} \pm \mathrm{s}, \mathrm{n}=5)$.

\begin{tabular}{lllllll} 
& $\mathrm{G}_{0} / \mathrm{G}_{1}(\%)$ & & $\mathrm{S}(\%)$ & & $\mathrm{G}_{2} / \mathrm{M}(\%)$ & \\
Day & Control & Hyperoxia & Control & Hyperoxia & Control & Hyperoxia \\
\hline $3 \mathrm{~d}$ & $75.25 \pm 1.50$ & $71.85 \pm 0.87$ & $8.21 \pm 3.87$ & $9.02 \pm 1.07$ & $16.57 \pm 2.68$ & $19.15 \pm 0.28$ \\
$7 \mathrm{~d}$ & $79.07 \pm 1.56$ & $67.25 \pm 3.45^{\mathrm{a}}$ & $8.29 \pm 0.72$ & $16.81 \pm 2.71^{\mathrm{a}}$ & $12.54 \pm 1.26$ & $19.67 \pm 3.60$ \\
$14 \mathrm{~d}$ & $83.69 \pm 0.96$ & $70.59 \pm 0.40^{\mathrm{b}}$ & $5.17 \pm 0.15$ & $25.75 \pm 0.80^{\mathrm{b}}$ & $11.00 \pm 1.38$ & $3.68 \pm 0.64$ \\
\hline
\end{tabular}

Note: Compare with control group, ${ }^{\mathrm{a} P}<0.05,{ }^{\mathrm{b}} \mathrm{P}<0.01$.

\section{Discussion}

CLD, caused by prolonged inhalation of high concentrations of oxygen, is a primary disease threatening the health and life of preterm children ${ }^{9,10}$. Although the exact pathogenesis of CLD is not well understood, the outcome of this pathological process is clearinterstitial pulmonary fibrosis ${ }^{11}$. Prevention and treatment of interstitial pulmonary fibrosis is a significant challenge in the treatment of CLD. LFs, the effector cells of pulmonary fibrosis, are capable of synthesizing extracellular matrix and cytokines ${ }^{12}$ and initiating the inflammatory response; these cells have a pro-fibrotic effect ${ }^{13}$. Pulmonary fibrosis is associated with excessively proliferating LFs that deposit in the interstitial lung or replace the normal lung epithelium ${ }^{14}$. LF hyper proliferation is a characteristic of CLD pulmonary fibrosis ${ }^{15}$.

Directly culturing LFs in vitro in the presence of high concentrations of oxygen inhibits cell proliferation; however, the opposite effects are observed in the LFs derived from the tissues of humans or animals that have inhaled high concentrations of oxygen. Therefore, primary cell culture of LFs derived from CLD neonatal rats is the only feasible method to study the cellular mechanism by which LFs undergo excessive proliferation. The biological characteristics of the primary cell cultures obtained from the donors did not change 
significantly, maintaining diploid genetic characteristics. The cells closely reflected in vivo growth characteristics, which is extremely important for the study of cell growth, differentiation, metabolism, and mechanisms of physiological and pathological changes. It is generally held that extracted primary LFs that show no significant differences in biological traits over less than four generations can be used for experiments. Therefore, in this study, we examined the biological behavior of the third-generation LF cells by establishing a reliable primary cell culture method for LFs derived from CLD newborn rats to create a platform to study the mechanism of CLD lung fibrosis in vitro.

Tissue injury and fibrosis replacement after injury are pathophysiological processes involving tissue repair ${ }^{16}$. How LF proliferation is temporally and appropriately regulated such that it does not affect tissue repair but initiates fibrosis is not clear. Exploring the mechanism of cell cycle regulation in proliferating LFs could possibly address this question. A growing body of research on the cell cycle suggests that cell proliferation is closely linked to the cell cycle. The cell cycle is a fundamental cellular process. A complete cell cycle includes $\mathrm{G1}, \mathrm{S}$, $G 2$, and $M$ phases. The proportion of cells in $G 1$ phase, the early DNA synthesis stage, is lower in highly proliferative cells. The proportion of cells in the DNA synthesis stage, $S$ phase, is higher in highly proliferative cells. $G 2$ and $M$ phases are the late DNA synthesis and mitosis stages, respectively. Two important cell cycle checkpoints, $\mathrm{G} 1 / \mathrm{S}$ and $\mathrm{G} 2 / \mathrm{M}$, regulate two key processes in the cell cycle, DNA replication and mitosis, respectively ${ }^{17}$. The $\mathrm{G} 1 / \mathrm{S}$ checkpoint is more important because it is the only point in the cycle that can be influenced by extrinsic proliferative and inhibitory information. Once cells undergo $\mathrm{G} 1 / \mathrm{S}$ and transition into $\mathrm{S}$ phase, DNA replication is successfully completed and cells easily undergo the other checkpoints and complete mitosis. DNA was marked by nucleic acid staining and analyzed using flow cytometry to calculate the distribution of cells in $\mathrm{G0} / \mathrm{G} 1, \mathrm{~S}$, and $\mathrm{G} 2 / \mathrm{M}$ phases. The proportion of highly proliferative cells in $S$ phase was elevated. In this study, the LF cells derived from newborn rats that had inhaled $90 \%$ oxygen for 3,7 , and $14 d$ were cultured to evaluate their proliferative state. FCM analysis showed that the proportion of LF cells in G1 phase of the cell cycle decreased with the increased exposure time to high oxygen, while the proportion of cells in the $S$ phase increased. No significant changes were observed in the proportion of cells in the G2/M phase. These findings indicated that high oxygen weakened the G1/S checkpoint, allowing more cells to transition from $\mathrm{G} 1$ to $\mathrm{S}$ phase and ultimately promoting fibroblast proliferation.

Caveolin-1 is highly expressed in type I alveolar epithelial cells, endothelial cells, and fibroblasts ${ }^{18}$. Studies have shown that caveolin-1 is associated with cell proliferation. Under normal physiological conditions, lung fibroblast growth is tightly regulated and lung collagen synthesis and degradation are in equilibrium. Lung fibroblasts play an important role in chronic pulmonary fibrosis formation caused by various factors. Zundel et al. ${ }^{19}$ observed that a decrease in caveolin-1 expression may significantly downregulate the ceramideinduced PI3K signaling pathway, allowing Rat1 fibroblasts to resist ceramide-induced apoptosis. However, increased caveolin-1 expression may alter PI3K activity, increasing the sensitivity of Rat1 fibroblasts to ceramideinduced apoptosis. Using antisense technology to decrease caveolin-1 expression in NIH/3T3, Liu et $a .^{20}$ found that cells with reduced caveolin-1 expression resist staurosporineinduced cell apoptosis, while increased expression restores $\mathrm{NIH} / 3 \mathrm{~T} 3$ cell sensitivity to apoptotic stimuli. After administering the PI3K/PKB pathway inhibitor LY2294002, $\mathrm{NIH} / 3 \mathrm{T3}$ cells have enhanced sensitivity to apoptotic stimuli. Wang et $\mathrm{al}^{21}$ reported that caveolin-1 expression is reduced in the lung tissues of patients with idiopathic pulmonary 
fibrosis. Stimulating primary cultured lung tissue fibroblasts and MRC25 with TGF- $\beta$ decreases the mRNA and protein expression of caveolin-1 in a time- and dose-dependent manner. Bleomycin or TGF- $\beta 1$ administered after caveolin-1 siRNA leads to increased $\alpha$-SMA expression, stimulating lung fibroblasts to transform into myofibroblasts. Conversely, an increase in caveolin-1 expression inhibits cell transformation ${ }^{22}$. In this study, LF cells from newborn rats that inhaled $90 \%$ oxygen for 3,7 , and $14 \mathrm{~d}$ were cultured. The role of caveolin-1 expression level in lungs fibroblast proliferation and the occurrence and development of pulmonary fibrosis through dynamic studying the caveolin-1 expression level of LF at different stages of development in hyperoxia-induced CLD rats. With longer exposure to high oxygen, caveolin-1 expression was significantly lower in the hyperoxic group than in the control group on days 7 and 14 . These data were consistent with the above report. LF cell proliferation showed the opposite trend. We observed that caveolin-1 downregulation was correlated to LF cell proliferation, suggesting caveolin-1 is involved in the incidence and development of CLD rat lung fibrosis. However, the mechanism underlying this effect is not clear and warrants further study.

\section{- Conclusions}

After exposure to hyperoxic conditions for $7 \mathrm{~d}$, LFs showed a marked increase in proliferation, while the expression of caveolin-1 began to decrease. The level of caveolin-1 expression was inversely related to LF proliferation.

\section{References}

1. Jensen EA, Schmidt B. Epidemiology of bronchopulmonary dysplasia. Birth Defects Res A Clin Mol Teratol. 2014 Mar;100(3):14557. doi: 10.1002/bdra.23235.

2. Ambalavanan N, Mourani P. Pulmonary hypertension in bronchopulmonary dysplasia. Birth Defects Res A Clin Mol Teratol. 2014 Mar;100(3):240-6. doi: 10.1002/bdra. 23241.

3. Chełstowska S, Wajs J, Rzepecki P, Płusa T. The role of fibrocytes in pulmonary fibrosis. Pol Merkur Lekarski. 2014 Jan;36(211):3941. PMID: 24645577.

4. Ansarie $M$, Naseem A, Kasmani A, Ahmed $\mathrm{R}$, Azeemuddin M. Profile of interstitial lung diseases in pakistan, karachi pulmonology clinics registry data: jan 2012 - aug 2013. Chest. 2014;145(3 Suppl):241A.

5. Wang XQ, Mao LJ, Fang QH, Kobayashi $T$, Kim $H J$, Sugiura $H$, Kawasaki $S$, Togo S, Kamio K, Liu X, Rennard SI. Sphingosylphosphorylcholine induces $\alpha$-smooth muscle actin expression in human lung fibroblasts and fibroblasts mediated gel contraction via S1P2 receptor and Rho/RhoKinase pathway. Prostaglandins Other Lipid Mediat. 2014 Jan;108:23-30. doi: 10.1016/j. prostaglandins.2014.02.002.

6. Cai L, Yi F, Dai Z, Huang X, Zhao YD, Mirza MK, Xu J, Vogel SM, Zhao YY. Loss of caveolin-1 and adiponectin induces severe inflammatory lung injury following LPS challenge through excessive oxidative/ nitrative stress. Am J Physiol Lung Cell Mol Physiol. 2014 Mar 15;306(6):L566-73. doi: 10.1152/ajplung.00182.2013.

7. Reese C, Perry B, Heywood J, Bonner M, Visconti RP, Lee R, Hatfield CM, Silver RM, Hoffman S, Tourkina E. Caveolin-1 deficiency predisposes African-Americans to SSc-ILD. Arthritis Rheumatol. 2014 Jul;66(7):190919. doi: 10.1002 /art.38572.

8. Kelleher MD, Naureckas ET, Solway $\mathrm{J}$, Hershenson MB. In vivo hyperoxic exposure increases cultured lung fibroblast proliferation and c-Ha-ras expression. Am J Respir Cell Mol Biol. 1995 Jan;12(1):19-26. doi: 10.1165/ajrcmb.12.1.7811467.

9. Lodha A, Sauvé R, Bhandari V, Tang S, Christianson $\mathrm{H}$, Bhandari $A$, Amin $\mathrm{H}$, Singhal N. Need for supplemental oxygen at discharge in infants with bronchopulmonary dysplasia is not associated with worse neurodevelopmental outcomes at 3 years corrected age. PLoS One. 2014 Mar 19;9(3):e90843. doi: 10.1371/journal. pone.0090843.

10.Murthy K, Savani RC, Lagatta JM, Zaniletti I, Wadhawan R, Truog W, Grover TR, Zhang H, Asselin JM, Durand DJ, Short BL, Pallotto EK, 
Padula MA, Dykes FD, Reber KM, Evans JR. Predicting death or tracheostomy placement in infants with severe bronchopulmonary dysplasia. J Perinatol. 2014 Jul;34(7):543-8. doi: 10.1038/jp.2014.35.

11.Jain D, Bancalari E. Bronchopulmonary dysplasia: Clinical perspective. Birth Defects Res A Clin Mol Teratol. 2014 Mar;100(3):13444. doi: 10.1002/bdra.23229.

12.Loomis-King $\mathrm{H}$, Flaherty KR, Moore BB. Pathogenesis, current treatments and future directions for idiopathic pulmonary fibrosis. Curr Opin Pharmacol. 2013 Jun;13(3):37785. doi: 10.1016/j.coph.2013.03.015.

13. Habiel DM, Hogaboam C. Heterogeneity in fibroblast proliferation and survival in idiopathic pulmonary fibrosis. Front Pharmacol. 2014 Jan 23;5:2. doi: 10.3389/ fphar.2014.00002.

14.Zhang L, Li Y, Liang C, Yang W. CCN5 overexpression inhibits profibrotic phenotypes via the PI3K/Akt signaling pathway in lung fibroblasts isolated from patients with idiopathic pulmonary fibrosis and in an in vivo model of lung fibrosis. Int J Mol Med. 2014 Feb;33(2):478-86. doi: 10.3892/ijmm.2013.1565.

15.Vuga LJ, Milosevic J, Pandit K, Ben-Yehudah A, Chu Y, Richards T, Sciurba J, Myerburg M, Zhang Y, Parwani AV, Gibson KF, Kaminski $\mathrm{N}$. Cartilage oligomeric matrix protein in idiopathic pulmonary fibrosis. PLoS One. 2013 Dec 20;8(12):e83120. doi: 10.1371/ journal.pone.0083120.

16. Woodcock HV, Molyneaux PL, Maher TM. Reducing lung function decline in patients with idiopathic pulmonary fibrosis: potential of nintedanib. Drug Des Devel Ther. 2013 Jun 19;7:503-10. doi: 10.2147/DDDT.S38833.
17.Yunlan L, Juan Z, Qingshan L. Antitumor activity of di-n-butyl-(2, 6-difluorobenzohydroxamato)tin(iv) against human gastric carcinoma SGC-7901 cells via $\mathrm{G} 2 / \mathrm{M}$ cell cycle arrest and cell apoptosis. PLoS One. 2014 Mar 18;9(3):e90793. doi: 10.1371/journal.pone.0090793.

18.Vandermeulen $E$, Ruttens $D$, Verleden SE, Vos $R$, Van Raemdonck DE, Kastelijn EA, Wauters E, Lambrechts D, Nawrot TS, Cox B, Verleden GM, Vanaudenaerde BM. Genetic variation in caveolin-1 affects survival after lung transplantation. Transplantation. 2014 Aug 15;98(3):354-9. doi: 10.1097/ TP.0000000000000058.

19.Zundel W, Swiersz LM, Giaccia A. Caveolin 1-mediated regulation of receptor tyrosine kinase-associated phosphatidylinositol 3-kinase activity by ceramide. Mol Cell Biol. 2000 Mar;20(5):1507-14. PMID: 10669728.

20.Liu J, Lee P, Galbiati F, Kitsis RN, Lisanti MP. Caveolin-1 expression sensitizes fibroblastic and epithelial cells to apoptotic stimulation. Am J Physiol Cell Physiol. 2001 Apr;280(4):C823-35. PMID: 11245599.

21. Wang XM, Zhang Y, Kim HP, Zhou Z, FeghaliBostwick CA, Liu F, Ifedigbo E, Xu X, Oury TD, Kaminski N, Choi AM. Caveolin-1: a critical regulator of lung fibrosis in idiopathic pulmonary fibrosis. J Exp Med. 2006 Dec 25;203(13):2895-906. doi: 10.1084/ jem.20061536.

22. Rathor N, Zhuang R, Wang JY, Donahue JM, Turner DJ, Rao JN. Src-mediated caveolin-1 phosphorylation regulates intestinal epithelial restitution by altering $\mathrm{Ca} 2+$ influx after wounding. Am J Physiol Gastrointest Liver Physiol. 2014 Apr 15;306(8):G650-8. doi: 10.1152/ajpgi.00003.2014.

\section{Correspondence:}

Xin-Dong Xue

Department of Pediatrics, Shengjing Hospital,

China Medical University

No. 36 Sanhao Street Heping District

Shenyang 110004

Liaoning, P.R. China

Phone: +86-18940251820

xindongxuecn@126.com

Received: Jan 15, 2017

Review: Mar 18, 2017

Accepted: Apr 19, 2017
Conflict of interest: none

Financial source: none 